\title{
Virulence characteristics and antimicrobial susceptibility of uropathogenic Escherichia coli strains
}

F.A. Oliveira ${ }^{1}$, K.S. Paludo ${ }^{2}$, L.N.V.S. Arend ${ }^{3}$, S.M.S.S. Farah ${ }^{3}$, F.O. Pedrosa ${ }^{4}$, E.M. Souza ${ }^{4}$, M. Surek ${ }^{1}$, G. Picheth ${ }^{1}$ and C.M.T. Fadel-Picheth ${ }^{1}$

${ }^{1}$ Departamento de Patologia Médica, Universidade Federal do Paraná, Curitiba, PR, Brasil

${ }^{2}$ Departamento de Biologia Estrutural Molecular e Genética, Universidade Estadual de Ponta Grossa, Ponta Grossa, PR, Brasil

${ }^{3}$ Laboratório Central do Estado do Paraná, Curitiba, PR, Brasil

${ }^{4}$ Departamento de Bioquímica e Biologia Molecular,

Universidade Federal do Paraná, Curitiba, PR, Brasil

Corresponding author: C.M.T. Fadel-Picheth

E-mail: fpicheth@ufpr.br

Genet. Mol. Res. 10 (4): 4114-4125 (2011)

Received March 21, 2011

Accepted September 12, 2011

Published October 31, 2011

DOI http://dx.doi.org/10.4238/2011.October.31.5

ABSTRACT. Eight virulence factors associated with uropathogenic
Escherichia coli (UPEC) were investigated in 204 clinical isolates of
E. coli recovered from urine cultures at counts $\geq 10^{5}$. The bacteria were
classified into two groups according to the number of leukocytes in
urine samples from which they were isolated: group I $\leq 8$ leukocytes/
hpf, 104 strains; group II $>8$ leukocytes/hpf, 100 strains. Two multiplex
PCR systems were used to detect genes encoding adhesin P (pap),
adhesin S ( $f f a)$, afimbrial adhesin I $(a f a)$, siderophore aerobactin
(aer), alpha-hemolysin ( $h l y)$, cytotoxic necrotizing factor type 1
(cnfl), and traT associated with serum resistance. The PAI marker
for the virulence island identified in strains CFT072 and CVD432,
a marker of enteroaggregative E. coli, was also investigated using 
PCR. The susceptibility profile of $E$. coli strains was determined by disk diffusion method. Ninety percent UPEC showed at least one of the virulence genes, the prevalence being $\operatorname{traT}(76 \%)$, aer (41\%), PAI (32\%), sfa (26\%), pap (25\%), cnfl (18\%), afa (6\%), and hly (5\%). There was no significant difference in the distribution of virulence genes between groups I and II. A significantly higher degree of virulence was detected in UPEC group II. The CVD432 gene was not detected in any of the UPECs. Fifty-nine percent of the strains were resistant to at least one of the antimicrobials that we tested; the most common being resistance to ampicillin (51\%) and trimethoprimsulfamethoxazole (44\%).

Key words: Escherichia coli; UPEC; Virulence genes; Uropathogen; Urinary tract infection; Antimicrobial resistance

\section{INTRODUCTION}

Urinary tract infection (UTI) is one of the most common bacterial infections (Zhang and Foxman, 2003; Stamm, 2006) and is defined as a significant number of pathogenic organisms in the urinary system (Zhang and Foxman, 2003; Marrs et al., 2005). Microscopy and culture of midstream urine is the gold standard diagnostic test for UTI. Quantitative bacteriuria of $10^{5}$ colony forming units per $\mathrm{mL}(\mathrm{CFU} / \mathrm{mL})$ is sufficient for a diagnosis of UTI (Chung et al., 2010). Clinical manifestations of UTI are very variable in extent and severity, while cystitis generally resolves without sequelae, pyelonephritis can cause serious morbidity and can be fatal.

Escherichia coli is a commensal of the human intestine, although several strains have acquired specific virulence attributes, which confer the ability to adapt to new niches and cause a broad spectrum of disease (Kaper et al., 2004). E. coli is by far the most common cause of UTI accounting for $80-90 \%$ of all UTIs seen among ambulatory populations (Zhang and Foxman, 2003; Stamm, 2006; Talan et al., 2008). These E. coli are named uropathogenic E. coli (UPEC) and have virulence properties that are associated with infection in the normal urinary tract including the expression of specific adhesins and toxins (Blanco et al., 1997a; Johnson and Stell, 2000; Kaper et al., 2004; Antão et al., 2009).

Bacterial adherence to uroepithelial cells is an essential stage for the initiation and development of UTI. This process allows bacteria to resist the flushing action of the urine flow and bladder emptying, promoting bacterial persistence and activation of the host signaling pathways. UPEC strains are able to produce various types of adhesins necessary for the recognition and attaching to receptors along the urinary tract including type 1 fimbriae, coded by the fim gene cluster; P fimbriae, coded by pap (pyelonephritis-associated pili) genes (Roberts et al., 1994; Antão et al., 2009); S fimbriae, coded by sfa genes (Korhonen et al., 1984; Antão et al., 2009); and Afa adhesins, coded by afa genes, for afimbrial adhesins (Blanco et al., 1997a; Johnson and Stell 2000; Kaper et al., 2004). It was shown that afa, pap and sfa are predictors of cystitis and/or pyelonephritis (Johnson et al., 2005).

Production of toxins such as hemolysin and cytotoxic necrotizing factor 1 (CNF1) causes tissue damage facilitating bacterial dissemination, releasing of host nutrients, and may 
also modulate host signaling pathways affecting several processes, including inflammatory responses, host cell survival, and cytoskeletal dynamics (Wiles et al., 2008b). It was shown that hemolysin provokes sloughing of the uroepithelium and bladder hemorrhage while CNF1 induces bladder inflammation and submucosal edema in mice (Smith et al., 2008).

Other characteristics are also important for the UPEC ability to cause UTI. Among them, the expression of iron acquisition systems that utilize siderophores to scavenge iron from the environment and subsequently concentrate it in the bacterial cytosol is fundamental for the ability to colonize and persist in host iron-poor niches such as the urinary tract since limiting iron availability is an important host defense against invading bacterial pathogens (Russo et al., 1999; Wiles et al., 2008b). Its importance is reflected by the presence of several iron acquisition systems in UPEC strains which are up regulated in vivo (Snyder et at., 2004). Also, the serum resistance, the ability to avoid the bactericidal activity of serum, is a characteristic important for pathogenesis enabling bacteria to persist in body fluids and internal organs. The outer membrane protein TraT play a role in the defense of bacteria against serum killing (Binns et al., 1982; Mellata et al., 2003).

Some recent studies have found markers of enteroaggregative E. coli (EAEC), a diarreagenic pathotype of E. coli, among UPEC strains suggesting that some EAEC are potentially uropathogens (Abe et al., 2008; Park et al., 2009).

In this study E. coli strains isolated from urine with bacterial counts $\geq 10^{5} \mathrm{CFU} / \mathrm{mL}$ were analyzed for presence of virulence factors and susceptibility to antimicrobials. The study was approved by the University's Research Ethics Committee.

\section{MATERIAL AND METHODS}

\section{Bacterial strains}

A total of 204 E. coli strains were isolated from urine samples of in- and out-patients in the Paraná Clínicas Laboratory in Curitiba, PR during the period of April to September 2010. UTI was confirmed by urine culture with bacterial counts $\geq 10^{5} \mathrm{CFU} / \mathrm{mL}$. Bacteria were identified using conventional microbiological methods and were divided into two groups according to the numbers of leukocytes present in the urine sample: discrete to moderate counts, $\leq 8 /$ hpf (group I, 104 strains) or high, $>8 / \mathrm{hpf}$ (group II, 100 strains). The bacteria were maintained in $\mathrm{TSB} / \mathrm{glycerol}$ at $-70^{\circ} \mathrm{C}$.

\section{Detection of virulence genes}

The E. coli strains were grown overnight in MacConkey agar and isolated colonies were used for DNA extraction by the boiling method. Two distinct multiplex PCR assays were used to detect the presence of the virulence genes. Multiplex 1 included primers designed by Yamamoto et al. (1995) for the target genes pap (pilus associated with pyelonephritis), afa (afimbrial adhesin), sfa (S fimbriae), which code for adhesins; hly (hemolysin) and cnfl (cytotoxic necrotizing factor 1) coding for toxins, and aer for siderophore aerobactin. Multiplex 2 contained primers PAI, a marker of the pathogenicity island of the pyelonephritogenic UPEC E. coli CFT073, and the serum resistance associated gene traT (Johnson and Stell, 2000). The primers sequences are in Table 1. 


\begin{tabular}{|c|c|c|c|}
\hline Primer & Sequence (5'-3') & Product size & Reference \\
\hline pap3 & GCAACAGCAACGCTGGTTGCATCAT & $336 \mathrm{bp}$ & Yamamoto et al., 1995 \\
\hline pap4 & AGAGAGAGCCACTCTTATACGGACA & & \\
\hline sfa1 & CTCCGGAGAACTGGGTGCATCTTAC & $410 \mathrm{bp}$ & Yamamoto et al., 1995 \\
\hline sfa2 & CGGAGGAGTAATTACAACCTGGCA & & \\
\hline afa1 & GCTGGGCAGCAAACTGATAACTCTC & $750 \mathrm{bp}$ & Yamamoto et al., 1995 \\
\hline afa2 & CATCAAGCTGTTTGTTCGTCCGCCCG & & \\
\hline hly1 & AACAAGGATAAGCACTGTTCTGGCT & $1177 \mathrm{bp}$ & Yamamoto et al., 1995 \\
\hline hly2 & ACCATATAAGCGGTCATTCCCGTCA & & \\
\hline aer1 & TACCGGATTGTCATATGCAGACCGT & $602 \mathrm{bp}$ & Yamamoto et al., 1995 \\
\hline aer2 & AATATCTTCCTCCAGTCCGGAGAAG & & \\
\hline cnfl & AAGATGGAGTTTCCTATGCAGGAG & 498 bp & Yamamoto et al., 1995 \\
\hline cnf2 & CATTCAGAGTCCTGCCCTCATTATT & & \\
\hline PAI F & GGACATCCTGGTACAGCGCGCA & $930 \mathrm{bp}$ & Johnson and Stell, 2000 \\
\hline PAI R & TCGCCACCAATCACAGCCGAAC & & \\
\hline $\operatorname{traT} F$ & GGTGTGGTGCGATGAGCACAG & $290 \mathrm{bp}$ & Johnson and Stell, 2000 \\
\hline $\operatorname{traT} \mathrm{R}$ & CACGGTTCAGCCATCCCTGAG & & \\
\hline
\end{tabular}

All the 204 UPEC strains were also tested for presence of CVD432, a plasmid sequence associated with enteroaggregative $E$. coli, using primers EAEC1 5'-CTGGCGAAAGACTGTATCAT-3' and EAEC2 5'-CAATGTATAGAAATCCGCTGTT-3' (Aranda et al., 2004).

The Multiplex PCR assays were performed in a final volume of $25 \mu \mathrm{L}$, containing DNA ( $2 \mu \mathrm{L}$ boiling lysate), $1.5 \mathrm{mM} \mathrm{MgCl} 2,0.2 \mathrm{mM}$ dNTP, $1 \mathrm{U}$ Taq DNA Polymerase (Fermentas), $1 \mathrm{X}$ Taq DNA Polymerase Buffer, and $0.4 \mu \mathrm{M}$ primers. For both multiplex systems the following program was used: 1 cycle of $94^{\circ} \mathrm{C}$ for $60 \mathrm{~s} ; 30$ cycles of $94^{\circ} \mathrm{C}$ for $60 \mathrm{~s}, 63^{\circ} \mathrm{C}$ for $30 \mathrm{~s}, 72^{\circ} \mathrm{C}$ for $90 \mathrm{~s}$ followed by a final cycle of $72^{\circ} \mathrm{C}$ for $300 \mathrm{~s}$.

Strains EC 2 (traT pap aer hly), EC 3 (PAI sfa cnfl) and EC 71 (afa), were used as positive controls. The detection of PCR products was performed on $2 \%$ agarose gel electrophoresis in TBE buffer ( $89 \mathrm{mM}$ Tris, $89 \mathrm{mM}$ boric acid, $2 \mathrm{mM}$ EDTA, $\mathrm{pH} 8.3$ ), stained with ethidium bromide $0.5 \mu \mathrm{g} / \mathrm{mL}$ and visualized under UV light.

\section{DNA sequencing}

The amplicons were sequenced using the DYEnamic ET Dye Terminator Cycle Sequencing kit (GE Healthcare Life Sciences) according to the manufacturer's instructions and an automatic DNA sequencer ABI Prism 377 (Applied Biosystems). Sequences were analyzed using the BioEdit, BLASTn and ClustalW softwares.

\section{Antimicrobial susceptibility testing}

The susceptibility test was carried out using the disk diffusion method according to the CLSI, 2010. The following antimicrobials were tested: amoxicillin-clavulanic acid, ampicillin, aztreonam, cefepime, cefoxitin, ceftriaxone, cephalothin, ciprofloxacin, gentamicin, nalidixic acid, trimethoprim/sulfamethoxazole and imipenem.

\section{Hemolysis assay}

The lytic capability of UPEC strains positive for hly gene was assessed by the 
method of Scheffer et al. (1988) with some modifications. Briefly, brain heart infusion (BHI) broth $(10 \mathrm{~mL})$ was inoculated with the E. coli strains and incubated at $37^{\circ} \mathrm{C}$ in an orbital shaker at $150 \mathrm{rpm}$. Aliquots of cultures were harvest at hourly intervals beginning after $4 \mathrm{~h}$ of incubation up to the 8 th hour. The cell suspensions or culture supernatant $(0.2$ $\mathrm{mL}$ ) were incubated for $2 \mathrm{~h}$ at $37^{\circ} \mathrm{C}$ with $0.2 \mathrm{~mL}$ suspension containing $10^{8} / \mathrm{mL}$ human erythrocytes in buffer $\left(20 \mathrm{mM} \mathrm{CaCl}_{2}, 10 \mathrm{mM}\right.$ Tris, and $140 \mathrm{mM} \mathrm{NaCl}, \mathrm{pH}$ 7.4). The hemoglobin released in the supernatant was determined at $540 \mathrm{~nm}$. The results are expressed as percent of lysis compared with that of erythrocytes lysed in distilled water and Triton $\mathrm{X}-1000.1 \%$.

\section{Statistical methods}

Comparisons for hemolytic assays were performed with one-way ANOVA and the Tukey post hoc test for average comparisons. Differences between non-continuous variables were tested by chi-square test or two-tailed Fisher exact test, as appropriate. The Pearson linear correlation test was used for correlation analysis. Statistical analyses were performed with Statistica for Windows, version 8.0 (StatSoft Inc., Tulsa, OK, USA). All results were considered as statistically significant at $\mathrm{P}<0.05$.

\section{RESULTS}

\section{Virulence-associated characteristics}

The marker CVD432 of plasmid pAA, associated with EAEC, was not found among the 204 UPEC strains analyzed. One hundred and eighty four strains $(90 \%)$, presented at least one of the eight UPEC virulence associated genes tested (Table 2), however in 20 strains $(10 \%)$ none of these virulence genes were found. Fifty-seven strains $(28 \%)$ had only one virulence gene; 45 strains (22\%) two genes; combinations of three virulence genes were observed in $40(20 \%)$ strains, and four to seven virulence genes in $42(20 \%)$. None of the strains contained all the eight UPEC virulence associated genes tested.

The two groups of strains are significantly different considering the number of virulence genes $(0,1,2,3$, or 4 - 7) present in each UPEC (Table 2). In group I, 39 strains contained only one virulence gene compared with 18 in group II $(\mathrm{P}=0.003)$. In contrast, group II contained 29 strains with 4 or more virulence genes compared with only 13 in group I $(\mathrm{P}=0.005)$. These results suggest that group I contains strains less virulent than those included in group II.

The prevalence of the UPEC virulence genes was traT (76\%), aer (41\%), PAI (32\%), sfa $(26 \%)$, pap (25\%), cnfl (18\%), afa (6\%) and hly (5\%). However, except for hly, found only in strains of group II, no significant difference was found in the distribution of these genes between the two groups of strains. The virulence associated genes were distributed in 50 distinct patterns; of these 20 were common to strains belonging to both groups of UPEC. Seven patterns were observed only in strains of group I, and 23 only among strains belonging to group II, suggesting that the last group present greater variability (Table 2). Significant correlations were observed between the presence of some of the virulence genes and leukocytes counts (Figure 1). 
Table 2. Distribution and frequency of virulence associated genes in UPEC strains.

\begin{tabular}{|c|c|c|c|}
\hline Genotype & Group 1 & Group 2 & Total \\
\hline $\operatorname{traT}$ & 34 & 17 & 51 \\
\hline aer & 4 & 1 & 5 \\
\hline pap & 1 & 0 & 1 \\
\hline traT aer & 11 & 10 & 21 \\
\hline $\operatorname{traT} P A I$ & 4 & 4 & 8 \\
\hline $\operatorname{traT} s f a$ & 1 & 1 & 2 \\
\hline $\operatorname{traT}$ afa & 1 & 0 & 1 \\
\hline traT pap & 0 & 2 & 2 \\
\hline PAI sfa & 3 & 2 & 5 \\
\hline PAI aer & 2 & 2 & 4 \\
\hline PAI pap & 0 & 1 & 1 \\
\hline afa aer & 1 & 0 & 1 \\
\hline traT pap aer & 2 & 8 & 10 \\
\hline traT PAI aer & 4 & 2 & 6 \\
\hline traT afa aer & 0 & 4 & 4 \\
\hline traT PAI pap & 2 & 2 & 4 \\
\hline traT PAI sfa & 1 & 2 & 3 \\
\hline traT sfa cnfl & 1 & 1 & 2 \\
\hline traT sfa aer & 1 & 1 & 2 \\
\hline traT pap cnfl & 0 & 1 & 1 \\
\hline traT aer cnfl & 0 & 1 & 1 \\
\hline PAI pap aer & 1 & 0 & 1 \\
\hline PAI sfa cnfl & 0 & 1 & 1 \\
\hline PAI sfa aer & 0 & 1 & 1 \\
\hline sfa aer cnfl 1 & 0 & 1 & 1 \\
\hline pap sfa cnf 1 & 2 & 0 & 2 \\
\hline pap afa aer & 1 & 0 & 1 \\
\hline traT pap sfa cnfl & 2 & 3 & 5 \\
\hline traT PAI sfa cnf1 & 3 & 1 & 4 \\
\hline traT PAI pap aer & 0 & 2 & 2 \\
\hline PAI pap sfa cnfI & 1 & 1 & 2 \\
\hline traT PAI pap cnfI & 0 & 1 & 1 \\
\hline traT pap sfa aer & 0 & 1 & 1 \\
\hline traT PAI afa aer & 1 & 1 & 2 \\
\hline traT sfa aer cnfl & 0 & 1 & 1 \\
\hline traT PAI sfa aer cnf 1 & 2 & 1 & 3 \\
\hline traT PAI pap aer hly & 0 & 3 & 3 \\
\hline traT pap sfa aer cnf 1 & 2 & 1 & 3 \\
\hline traT PAI pap sfa cnfI & 1 & 1 & 2 \\
\hline traT PAI sfa cnfl hly & 0 & 2 & 2 \\
\hline traT PAI pap sfa aer & 0 & 1 & 1 \\
\hline traT PAI sfa afa aer & 0 & 1 & 1 \\
\hline PAI pap sfa aer hly & 0 & 1 & 1 \\
\hline PAI pap sfa cnf1 aer & 0 & 1 & 1 \\
\hline traT PAI pap sfa aer cnfI & 1 & 0 & 1 \\
\hline traT PAI pap sfa aer hly & 0 & 2 & 2 \\
\hline traT PAI sfa afa aer cnfl & 0 & 1 & 1 \\
\hline traT PAI pap afa aer hly & 0 & 1 & 1 \\
\hline PAI pap sfa aer cnfl hly & 0 & 1 & 1 \\
\hline traT PAI pap sfa aer cnfl hly & 0 & 1 & 1 \\
\hline
\end{tabular}

The number of leukocytes was positively correlated with the marker for pathogenicity island PAI $(\mathrm{p}=0.022)$, pap $(\mathrm{P}=0.002)$, aer $(\mathrm{P}=0.005)$ and hly $(\mathrm{P}<0.001)$, indicating that the greater the leukocyte number the more frequent these virulence genes are found. Also a positive correlation of $0.702(\mathrm{P}<0.001)$ was observed between $c n f l$ (found in 36 strains) and $s f a$ (present in 53 strains) which were found together in 32 strains. 


\begin{tabular}{|c|c|c|c|c|c|c|c|c|c|}
\hline & traT & PAI & pap & sfa & $a f a$ & aer & cnfl & $h i v$ & Leu \\
\hline traT & $\mathrm{NA}$ & & & & & & & & \\
\hline PAI & - & NA & & & & & & & \\
\hline pap & - & $\begin{array}{l}0.212 \\
P=0.002\end{array}$ & $\mathrm{NA}$ & & & & & & \\
\hline sfa & - & $\begin{array}{l}0.386 \\
\mathrm{P}<0.001\end{array}$ & $\begin{array}{l}0.266 \\
P<0.001\end{array}$ & $\mathrm{NA}$ & & & & & \\
\hline afa & - & - & - & - & $\mathrm{NA}$ & & & & \\
\hline$a \in r$ & - & - & $\begin{array}{l}0.214 \\
P=0.002\end{array}$ & - & $\begin{array}{l}0.255 \\
P<0.001\end{array}$ & NA & & & \\
\hline$c n f l$ & - & $\begin{array}{l}0.227 \\
P=0.001\end{array}$ & $\begin{array}{l}0.332 \\
P<0.001\end{array}$ & $\begin{array}{l}0.702 \\
P<0.001\end{array}$ & - & - & NA & & \\
\hline$h l v$ & - & $\begin{array}{l}0.344 \\
P<0.001\end{array}$ & $\begin{array}{l}0.317 \\
P<0.001\end{array}$ & $\begin{array}{l}0.208 \\
P=0.003\end{array}$ & - & $\begin{array}{l}0.196 \\
P=0.005\end{array}$ & - & $\mathrm{NA}$ & \\
\hline Leu & - & $\begin{array}{l}0.162 \\
P=0.022\end{array}$ & $\begin{array}{l}0.218 \\
P=0.002\end{array}$ & - & - & $\begin{array}{l}0.198 \\
P=0.005\end{array}$ & - & $\begin{array}{l}0.245 \\
P<0.001\end{array}$ & NA \\
\hline
\end{tabular}

Figure 1. Correlation analysis between virulence genes. The correlation and results of the Fischer exact test indicating only the significant $\mathrm{P}$ values are indicated. $\mathrm{Leu}=$ leukocytes.

The strains positive for $h l y$ were tested for the ability to cause lysis of human erythrocytes. Eight of the ten strains presented hemolytic activity (Table 3). The hemolytic activity of bacterial cultures was determined at different times during cell growth. E. coli strains induced hemolysis mainly after 3-4 h of bacterial growth. Then, the hemolysis induction rapidly decreased, as previously described (Scheffer et al, 1988; Johnson, 1991). Two strains failed to produce significant hemolysis, however, since HlyA is a pore-forming toxin, at low concentration its binding not always lead to lysis (Boehm et al, 1990; Ostolaza and Goni,1995).

Table 3. Lytic capability of UPEC strains.
\begin{tabular}{lc}
\hline Strain & Hemolysis $(\%$ \\
\hline Negative control & $3,46 \pm 0,14$ \\
UPEC $h l y$ negative & $4,10 \pm 0,80$ \\
UPEC 39 & $11,6 \pm 0,67$ \\
UPEC 40 & $12,63 \pm 0,76$ \\
UPEC 44 & $50,4 \pm 5,51^{* * *}$ \\
UPEC 74 & $34,49 \pm 1,69^{* * *}$ \\
UPEC 90 & $21,87 \pm 2,4^{* * *}$ \\
UPEC 92 & $24,7 \pm 3,21^{* * *}$ \\
UPEC 105 & $64,2 \pm 13,24^{* * *}$ \\
UPEC 134 & $16,97 \pm 2,4^{* *}$ \\
UPEC 145 & $41,6 \pm 2,99^{* * *}$ \\
UPEC 162 & $41,6 \pm 2,24^{* * *}$ \\
\hline
\end{tabular}

**P $<0.01$ and $* * * \mathrm{P}<0.001$, compared with negative control.

\section{Antimicrobial susceptibility test}

One hundred and twenty strains (59\%) showed resistance to one or more antimicrobials (Table 4). Resistance was observed for all the antimicrobials tested: ampicillin (51\%), trimethoprim / sulfamethoxazole (44\%), nalidixic acid (21\%), gentamicin (16\%), ciprofloxacin (13\%), cephalothin (4\%), cefoxitin (1\%), amoxicillin-clavulanic acid (1\%), ceftriaxone, $(1 \%)$, 
aztreonam, cefepime and imipenem ( $0.5 \%$ each). Resistance to ampicillin and sulfametoxazol/ trimetoprim (30\%), ampicillin (13\%), and ampicillin, ciprofloxacin, nalidixic acid and sulfametoxazol/trimetoprim (9\%) were the most common (Table 4). Fifty-one (42\%) of these strains were multi-resistant, and a possible ESBL-producing strain was found.

Table 4. Antimicrobial resistance patterns found in UPEC strains.

\begin{tabular}{|c|c|}
\hline Antimicrobial & Strains $(\%)$ \\
\hline Ampicillin, Trimethoprim/sulfamethoxazole & $36(30)$ \\
\hline Ampicillin & $16(13)$ \\
\hline Ampicillin, Nalidixic acid, Trimethoprim/sulfamethoxazole & $11(9)$ \\
\hline Ampicillin, Ciprofloxacin, Gentamicin, Nalidixic acid, Trimethoprim/sulfamethoxazole & $6(5)$ \\
\hline Gentamicin & $6(5)$ \\
\hline Trimethoprim/sulfamethoxazole & $6(5)$ \\
\hline Ampicillin, Gentamicin, Trimethoprim/sulfamethoxazole & $6(5)$ \\
\hline Ampicillin, Ciprofloxacin, Nalidixic acid, Trimethoprim/sulfamethoxazole & $5(4)$ \\
\hline Ampicillin, Cephalothin, Trimethoprim/sulfamethoxazole & $5(4)$ \\
\hline Ampicillin, Gentamicin, Nalidixic acid, Trimethoprim/sulfamethoxazole & $4(3)$ \\
\hline Cephalothin & $2(2)$ \\
\hline Ampicillin, Ciprofloxacin, Nalidixic acid & $2(2)$ \\
\hline Ampicillin, Cephalothin, Ciprofloxacin, Nalidixic acid, Trimethoprim/sulfamethoxazole & $2(2)$ \\
\hline Nalidixic acid & $1(1)$ \\
\hline Ampicillin, Ciprofloxacin & $1(1)$ \\
\hline Ampicillin, Nalidixic acid & $1(1)$ \\
\hline Gentamicin, Trimethoprim/sulfamethoxazole & $1(1)$ \\
\hline Ampicillin, Gentamicin, Nalidixic acid & $1(1)$ \\
\hline Ampicillin, Gentamicin, Nalidixic acid, Trimethoprim/sulfamethoxazole & $1(1)$ \\
\hline Ampicillin, Cephalothin, Gentamicin, Nalidixic acid, Trimethoprim/sulfamethoxazole & $1(1)$ \\
\hline Ampicillin, Ceftriaxone, Ciprofloxacin, Gentamicin, Nalidixic acid & $1(1)$ \\
\hline Ampicillin, Amoxicillin-clavulanic acid, Cefoxitin, Gentamicin, Nalidixic acid & $1(1)$ \\
\hline Ampicillin, Cefoxitin, Ciprofloxacin, Nalidixic acid, Trimethoprim/sulfamethoxazole & $1(1)$ \\
\hline $\begin{array}{l}\text { Ampicillin, Amoxicillin-clavulanic acid, Ciprofloxacin, Gentamicin, Nalidixic acid, } \\
\text { Trimethoprim/sulfamethoxazole }\end{array}$ & $1(1)$ \\
\hline Ampicillin, Ciprofloxacin, Gentamicin, Imipenem, Nalidixic acid, Trimethoprim/sulfamethoxazole & $1(1)$ \\
\hline $\begin{array}{l}\text { Ampicillin, Aztreonam, Cefepime, Ceftriaxone, Cephalotin, Ciprofloxacin, Gentamicin, Nalidixic acid, } \\
\text { Trimethoprim/sulfamethoxazole }\end{array}$ & $1(1)$ \\
\hline
\end{tabular}

\section{DISCUSSION}

Recent studies have shown that some UPEC strains share some characteristics of EAEC (Abe et al., 2008; Park et al., 2009), a pathotype of diarrheagenic E. coli defined by characteristic aggregative adherence pattern to HEp-2 cells. Although no single virulence factor has been irrefutably associated with EAEC virulence, several of them are regulated by a single transcriptional factor called AggR coded by the $\operatorname{aggR}$ gene (Kaper et al., 2004). The pattern of aggregative adherence was observed in $4 \%$ of UPEC strains, while the aggR gene was found in $3.1 \%$ (Abe et al., 2008) or 41\% (Park et al., 2009) of isolates. Also the aatA gene, which code for the dispersin transporter protein complex, formerly known as EAEC or CVD432 gene, was detected in 3.6\% of UPEC strains (Abe et al., 2008). These results are in contrast with those found in the present work where no positive results for CVD 432 were found among the 204 UPEC strains tested. These discrepancies might be explained by the loss or absence of the plasmid that contains the EAEC sequences in the UPEC strains analyzed in this study, and also to heterogeneity in gene composition of the plasmid pAA associated with EAEC.

In $10 \%$ of strains analyzed in this work none of the eight UPEC associated virulence genes tested were found. Lack of virulence markers was also observed in other studies i.e. 
41 and $51 \%$ of UPEC strains when tested respectively for presence of hly, cnfl, pap, sfa and afa (Blanco et al., 1997b) or pap, sfa and afa (Santo et al., 2006). These findings reflect the heterogeneity in the distribution of virulence genes among UPEC strains and the complex and multifactorial characteristic of UPEC virulence (Johnson and Stell, 2000; Snyder et al., 2004).

Several distinct patterns were found among the UPEC strains regarding the number of virulence genes and their distribution among the strains (Table 2), a result also found in other studies (Blanco et al., 1997b; Johnson and Stell, 2000; Marrs et al., 2002). High heterogeneity of the composition of virulence associated genes was found, and except for strains carrying only traT (51 strains, $25 \%$ ), or traT aer (21 strains, 10\%), most strains have a unique virulence gene pattern (Table 2). Similar finding was also observed by Marrs et al. (2002), who found that only 5 to $10 \%$ of UPEC strains shared virulence gene patterns.

A significant difference was found among strains belonging to group I or II. A higher degree of virulence was found for UPEC of group II, associated with intense leukocyturia. This group contained a higher number of strains carrying multiple virulence genes $(\mathrm{P}=0.005)$. Strains with only one virulence gene $(\mathrm{P}=0.003)$, predominate in group I (milder leukocyturia). However, no statistically significant difference was found in the distribution of virulence genes between the two groups, except for $h l y(\mathrm{P}=0.033)$, which was found only in strains of group II. Eighty percent of the strains positive for $h l y$ induced significant lysis of human erythrocytes. $\alpha$-hemolysin (HlyA), is associated with higher clinical severity in UTI patients (Johnson, 1991; Marrs et al, 2005). Even sublytic concentrations of HlyA can produce inactivation of the serine/ threonine kinase Akt, which plays a central role in host cell cycle progression, metabolism, vesicular trafficking, survival, and inflammatory signaling pathways (Wiles et al., 2008a).

The $\operatorname{traT}$ gene, associated with serum resistance, was the most prevalent, present in $77 \%$ of strains. Johnson and Stell (2000) found traT frequencies ranging from 59 to $83 \%$ according to the carboxylesterase B type and presence of PAI, whose frequency ranged from 26 to $96 \%$. In the present work the PAI frequency was $33 \%$, and no correlation was found between PAI and traT gene, which may be associated to differences in the distribution of traT bearing plasmids and variability of pathogenicity islands described in UPEC strains (Binns et al., 1892; Lloyd et al., 2007).

The adhesins genes $s f a$ and pap presented frequencies of 26 and $25 \%$, respectively. Frequencies of $s f a$ and pap varying from 0 to $64 \%$ and from 0 to $54 \%$, respectively, have been reported in strains isolated from distinct groups of patients and belonging to different phylogenetic groups of UPEC (Blanco et al., 1997a; Santo et al., 2006; Takahashi et al., 2006, 2009). A significant positive correlation was found for simultaneous presence of $s f a$ and pap $(\mathrm{P}<$ 0.001 ), which were found together in $11 \%$ of the strains. Since the binding to the host cells is a key factor for development of infection, the expression of different types of adhesins, with affinity to distinct specific receptors, confers advantages to pathogens (Antão et al., 2009).

The afa gene presented the lowest frequency among the adhesins, being found in $6 \%$ of the strains. Frequencies of afa ranging from 2 to $11 \%$ have been reported (Blanco et al., 1997a; Santo et al., 2006; Takahashi et al., 2006; Abe et al., 2008) indicating a lower prevalence of this gene among UPEC.

Among the toxin genes, cnfl was the most prevalent, present in $18 \%$ of strains, while hly was detected in only $5 \%$ of the strains, all belonging to group 2 . Prevalence of these genes vary according to the phylogenetic group, clinical conditions of host and geographical localization. Frequencies ranging from 0 to $32 \%$ were found for $c n f l$; and from 0 to $44 \%$ for $h l y$ 
(Blanco et al., 1997b; Johnson and Stell, 2000; Takahashi et al., 2006, 2009; Abe et al., 2008). Prevalence of aer was $41 \%$, which is similar to those found in other studies, although a large variation in gene frequencies has also been been observed (Abe et al., 2008; Takahashi et al., 2006, 2009).

Several pathogenicity islands, with distinct genetic compositions, have been described in UPEC strains. The combination of the virulence genes pap aer hly (Table 2), found in 9 strains, suggest the presence of the pathogenicity island I described in strain CFT073 (Guyer et al., 1998; Lloyd et al., 2007). The best studied UPEC strains such as CFT073, J96, 536 and UTI89 have one or more pathogenicity island. Associations of the genes pap, hly and cnfl and also $s f a$ are present in some of them (Guyer et al., 1998; Oelschlaeger et al., 2002; Lloyd et al., 2007; Wiles et al., 2008b). Associations of two or more of these genes were observed in some of the strains analyzed in this study, which is suggestive of the presence of pathogenicity island in these strains. For example, the strong positive correlation $(\mathrm{P}<0.001$; Figure 1$)$ found between $c n f 1$ and $s f a$ may be a result of physical linkage between them, thus suggesting the presence of a pathogenicity island

UTIs are common infections and increased antimicrobial resistance hinder their treatment. The most commonly used antibacterial drugs in the treatment of UTI are trimethoprimsulfamethoxazole, cephalosporins, semi-synthetic penicillins with or without beta-lactamase inhibitors and quinolones (Arslan et al., 2005; Chung et al., 2010). A high frequency (59\%) of UPEC strains resistant to one or more antimicrobials was found in the present work (Table 4). The most frequent antimicrobial resistance found was against ampicillin (51\%), in agreement with other studies that found ampicillin resistance ranging from 30 to 58\% (McIsaac et al., 2004; Arslan et al., 2005; Houdouin et al., 2006; Talan et al., 2008). The second most frequent resistance observed in this work was to trimethoprim/sulfamethoxazole (44\%), again a common finding, with frequencies varying from 10.9 to 36\% world-wide (McIsaac et al., 2004; Arslan et al., 2005; Houdouin et al., 2006; Talan et al., 2008). Resistance to ciprofloxacin, also frequently used in the treatment of UTI, was found in 13\% of strains; other studies found frequencies of 3\% (Talan et al., 2008), 9\% (Houdouin et al., 2006) and 17\% (Arslan et al., 2005). These results show that resistance to the most frequently used antimicrobials agents are found in a high percentage of UPEC isolates, a cause for concern since this reduces the firstline alternatives for therapy.

A relationship between UPEC reduced virulence and antimicrobial resistance to quinolone and fluoroquinolone was observed in several studies. Nalidixic acid resistance was associated with a lower prevalence of $s f a$, pathogenicity island $\mathrm{II}_{\mathrm{J96}}$-like domains, strains of the phylogenetics subgroup B2/I, and group A (Houdouin et al., 2006). Piatti et al. (2008), found a higher prevalence of fluoroquinolone susceptible strains in the phylogenetic group B2. Also hly and cnfl were found to be associated with susceptibility to fluoquinolone and with group B2. Moreover, within group B2, fluoroquinolone resistant strains showed lower prevalences of pap, hly and cnfl than their susceptible counterparts. Similar results were also found by Takahashi et al. (2009). In our work no statistical significant difference was found between quinolone and fluoroquinolone resistant strains and prevalence of virulence genes, indicating that the relationship may be influenced by the genetic background.

In summary, a high variability was found among UPEC strains regarding the distribution of virulence genes and more virulent strains were isolated from urine samples with stronger inflammatory response. A high level of resistance was found due to antimicrobials frequently used for UTI treatment. 


\title{
ACKNOWLEDGMENTS
}

\author{
Research supported by Fundação Araucária.
}

\section{REFERENCES}

Abe CM, Salvador FA, Falsetti IN, Vieira MA, et al. (2008). Uropathogenic Escherichia coli (UPEC) strains may carry virulence properties of diarrhoeagenic E. coli. FEMS Immunol. Med. Microbiol. 52: 397-406.

Antão EM, Wieler LH and Ewers C (2009). Adhesive threads of extraintestinal pathogenic Escherichia coli. Gut. Pathog. 1: 22.

Aranda KR, Fagundes-Neto U and Scaletsky IC (2004). Evaluation of multiplex PCRs for diagnosis of infection with diarrheagenic Escherichia coli and Shigella spp. J. Clin. Microbiol. 42: 5849-5853.

Arslan H, Azap OK, Ergönül Ö and Timurkaynak F (2005). Risk factors for ciprofloxacin resistance among Escherichia coli strains isolated from community-adquired urinary tract infections in Turkey. J. Antimicrob. Chemother. 56: 914-918.

Binns MM, Mayden J and Levine RP (1982). Further characterization of complement resistance conferred on Escherichia coli by the plasmid genes traT of R100 and iss of ColV,I-K94. Infect. Immun. 35: 654-659.

Blanco M, Blanco JE, Alonso MP, Mora et al. (1997a). Detection of pap, sfa and afa adhesin-encoding operons in uropathogenic Escherichia coli strains: relationship with expression of adhesins and production of toxins. Res. Microbial. 148:745-755.

Blanco M, Blanco JE, Rodriguez E, Abalia I, et al. (1997b). Detection of virulence genes in uropathogenic Escherichia coli by polymerase chain reaction (PCR): comparison with results obtained using phenotypic methods. J. Clin. Micro. 31: 37-43.

Boehm DF, Welch RA and Snyder IS (1990). Domains of Escherichia coli hemolysin (HlyA) involved in binding of calcium and erythrocyte membranes. Infect. Immun. 58: 1959-1964.

Chung A, Arianayagam M and Rashid P (2010). Bacterial cystitis in women. Aust. Fam. Physician. 39: 295-298.

CLSI (2010). Performance Standards for Antimicrobial Susceptibility Testing; Twentieth Informational Supplement. Clinical and Laboratory Standards Institute, Wayne.

Guyer DM, Kao JS and Mobley HL (1998). Genomic analysis of a pathogenicity island in uropathogenic Escherichia coli CFT073: distribution of homologous sequences among isolates from patients with pyelonephritis, cystitis, and Catheter-associated bacteriuria and from fecal samples. Infect. Immun. 66: 4411-4417.

Houdouin V, Bonacorsi S, Bidet P, Bingen-Bidois M, et al. (2006). Phylogenetic background and carriage of pathogenicity island-like domains in relation to antibiotic resistance profiles among Escherichia coli urosepsis isolates. $J$. Antimicrob. Chemother. 58: 748-751.

Johnson JR (1991). Virulence factors in Escherichia coli urinary tract infection. Clin. Microbiol. Rev. 4: 80-128.

Johnson JR and Stell AL (2000). Extended virulence genotypes of Escherichia coli strains from patients with urosepsis in relation to phylogeny and host compromise. J. Infect. Dis. 181: 261-272.

Johnson JR, Owens K, Gajewski A and Kuskowski MA (2005). Bacterial characteristics in relation to clinical source of Escherichia coli isolates from women with acute cystitis or pyelonephritis and uninfected women. J. Clin. Microbiol. 43: 6064-6072.

Kaper JB, Nataro JP and Mobley HL (2004). Pathogenic Escherichia coli. Nat. Rev. Microbiol. 2: 123-140.

Korhonen TK, Vaisanen-Rhen V, Rhen M, Pere A, et al. (1984). Escherichia coli fimbriae recognizing sialyl galactosides. J. Bacteriol. 159: 762-766.

Lloyd AL, Rasko DA and Mobley HLT (2007). Defining genomic islands and uropathogen-specific genes in uropathogenic Escherichia coli. J. Bacteriol. 189: 3532-3546.

Marrs CF, Zhang L, Tallman P, Manning SD, et al. (2002). Variations in 10 putative uropathogen virulence genes among urinary, faecal and peri-urethral Escherichia coli. J. Med. Microbiol. 51: 138-142.

Marrs CF, Zhang L and Foxman B (2005). Escherichia coli mediated urinary tract infections: are there distinct uropathogenic E. coli (UPEC) pathotypes? FEMS Microbiol. Lett. 252: 183-190.

McIsaac J, Mazzulli T, Moineddin R, Raboud J, et al. (2004). Uropathogen antibiotic resistance in adult women presenting to family physicians with acute uncomplicated cystitis. Can. J. Infect. Dis. Med. Microbiol. 15: 266-270.

Mellata M, Dho-Moulin M, Dozois CM, Curtiss R, III, et al. (2003). Role of virulence factors in resistance of avian pathogenic Escherichia coli to serum and in pathogenicity. Infect. Immun. 71: 536-540.

Oelschlaeger TA, Dobrindt U and Hacker J (2002). Pathogenicity islands of uropathogenic E. coli and the evolution of virulence. Int. J. Antimicrob. Agents 19: 517-521.

Ostolaza H and Goni FM (1995). Interaction of the bacterial protein toxin alpha-haemolysin with model membranes:

Genetics and Molecular Research 10 (4): 4114-4125 (2011)

CFUNPEC-RP www.funpecrp.com.br 
protein binding does not always lead to lytic activity. FEBS Lett. 371: 303-306.

Park HK, Jung YJ, Chae HC, Shin YJ, et al. (2009). Comparison of Escherichia coli uropathogenic genes (kps, usp and ireA) and enteroaggregative genes (aggR and aap) via multiplex polymerase chain reaction from suprapubic urine specimens of young children with fever. Scand. J. Urol. Nephrol. 43: 51-57.

Piatti G, Mannini A, Balistreri M and Schito AM (2008). Virulence factors in urinary Escherichia coli strains: phylogenetic background and quinolone and fluoroquinolone resistance. J. Clin. Microbiol. 46: 480-487.

Roberts JA, Britt-Inger M, Ilver D, Haslam D, et al. (1994). The Gal(al-4)Gal-specific tip adhesin of Escherichia coli P-fimbriae is needed for pyelonephritis to occur in the normal urinary tract. Proc. Natl. Acad. Sci. U. S. A. 91: 11889-11893.

Russo TA, Carlino UB, Mong A and Jodush ST (1999). Identification of genes in an extraintestinal isolate of Escherichia coli with increased expression after exposure to human urine. Infect. Immun. 67: 5306-5314.

Santo E, Macedo C and Marin JM (2006). Virulence factors of uropathogenic Escherichia coli from a university hospital in Ribeirão Preto, São Paulo, Brazil. Rev. Inst. Med. Trop. São Paulo 48: 185-188.

Scheffer J, Konig W, Braun V and Goebel W (1988). Comparison of four hemolysin-producing organisms (Escherichia coli, Serratia marcescens, Aeromonas hydrophila, and Listeria monocytogenes) for release of inflammatory mediators from various cells. J. Clin. Microbiol. 26: 544-551.

Smith YC, Rasmussen SB, Grande KK, Conran RM, et al. (2008). Hemolysin of uropathogenic Escherichia coli evokes extensive shedding of the uroepithelium and hemorrhage in bladder tissue within the first 24 hours after intraurethral inoculation of mice. Infect. Immun. 76: 2978-2990.

Snyder JA, Haugen BJ, Buckles EL, Lockatell CV, et al. (2004). Transcriptome of uropathogenic Escherichia coli during urinary tract infection. Infect. Immun. 72: 6373-6381.

Stamm WE (2006). Theodore E. Woodward Award: host-pathogen interactions in community-acquired urinary tract infections. Trans. Am. Clin. Climatol. Assoc. 117: 75-83.

Takahashi A, Kanamaru S, Kurazono H, Kunishima Y, et al. (2006). Escherichia coli isolates associated with uncomplicated and complicated cystitis and asymptomatic bacteriuria possess similar phylogenies, virulence genes, and O-serogroup profiles. J. Clin. Microbiol. 44: 4589-4592.

Takahashi A, Muratani T, Yasuda M, Takahashi S, et al. (2009). Genetic profiles of fluoroquinolone-resistant Escherichia coli isolates obtained from patients with cystitis: phylogeny, virulence factors, PAI $u s p$ subtypes, and mutation patterns. J. Clin. Microbiol. 47: 791-795.

Talan DA, Krishnadasan A, Abrahamian FM, Stamm WE, et al. (2008). Prevalence and risk factor analysis of trimethoprimsulfamethoxazole - and fluoroquinolone-resistant Escherichia coli infection among emergency department patients with pyelonephritis. Clin. Infect. Dis. 47: 1150-1158.

Wiles TJ, Dhakal BK, Eto DS and Mulvey MA (2008a). Inactivation of host Akt/protein kinase B signaling by bacterial pore-forming toxins. Mol. Biol. Cell 19: 1427-1438.

Wiles TJ, Kulesus RR and Mulvey MA (2008b). Origins and virulence mechanisms of uropathogenic Escherichia coli. Exp. Mol. Pathol. 85: 11-19.

Yamamoto S, Terai A, Yuri K, Kurazono H, et al. (1995). Detection of urovirulence factors in Escherichia coli by multiplex polymerase chain reaction. FEMS Immunol. Med. Microbiol. 12: 85-90.

Zhang L and Foxman B (2003). Molecular epidemiology of Escherichia coli mediated urinary tract infections. Front Biosci. 8: e235-e244. 